\title{
Account
}

\section{Dynamic Kinetic Resolutions and Asymmetric Transformations by Enzyme-Metal Combo Catalysis}

\author{
Mahn-Joo Kim," Yangsoo Ahn, and Jaiwook Park ${ }^{*}$ \\ National Research Laboratory of Chirotechnology and Department of Chemistry, Division of Molecular and Life Sciences, \\ Pohang University of Science and Technology, Pohang, Kyongbuk 790-784, Korea. "E-mail: mjkim@ postech.ac.kr
}

Received February 28, 2005

\begin{abstract}
Enzyme-metal combo catalysis is described as a useful methodology for the synthesis of optically active compounds. The key point of the method is the use of enzyme and metal in combination as the catalysts for the complete transformation of racemic substrates to single enantiomeric products through dynamic kinetic resolution (DKR). In this approach, enzyme acts as an enantioselective resolving catalyst and metal does as a racemizing catalyst for the efficient DKR. Three kinds of enzyme-metal combinations - lipase-ruthenium, subtilisin-ruthenium, and lipase-palladium - have been developed as the catalysts for the DKRs of racemic alcohols, esters, and amines. The scope of the combination catalysts can be extended to the asymmetric transformations of ketones, enol acetates, and ketoximes via the DKRs. In most cases studied, enzyme-metal combo catalysis provided enantiomerically-enriched products in high yields.
\end{abstract}

Key Words : Catalytic racemization, Dynamic kinetic resolution, Asymmetric transformation, Enzyme-metal combo catalysis, Chirotechnology

\section{Introduction}

The methods for the synthesis of optically pure compounds are of great importance in pharmaceutical, agrochemical, and other fine chemical industries. ${ }^{1}$ One of the popular methods is the kinetic resolution (KR) of racemic mixtures by enzymes such as lipases and esterases. ${ }^{2,3}$ The methodology has been widely used for the preparation of optically pure alcohols, acids, and their esters. However, KR has an intrinsic limitation; the yield cannot exceed $50 \%$ for a single enantiomer. Thus, the conventional KR usually is accompanied by additional processes; separation, racemization, and recycling of unwanted enantiomers. The limitation, however, can be overcome if the kinetic resolution could be transformed to the dynamic kinetic resolution (DKR) by being coupled with a racemization reaction for the in situ conversion of unwanted enantiomers to products. ${ }^{4}$

Recently, several groups have reported the use of a metal complex as the racemizing catalyst with an enzyme for the DKR. ${ }^{5}$ Williams et al. reported a lipase-palladium combination for the DKR of allyl acetates ${ }^{6}$ and a lipase-rhodium combination for the DKR of secondary alcohols. ${ }^{7}$ In the same year, Reetz et al. reported the DKR of 1-phenylethylamine by a lipase-palladium combination. ${ }^{8}$ Soon after, we and the Bäckvall group reported substantially improved DKRs of secondary alcohols. In particular, we developed a new racemizing catalyst for the efficient DKRs of alcohols, which displayed high activity at room temperature. ${ }^{9}$ The room-temperature DKRs were successfully done with both lipase and subtilisin to provides $(R)$ - and $(S)$-products, respectively. The DKRs by enzyme-metal combinations have been extended to the asymmetric transformations of ketones, enol esters, and ketoximes.

This account covers the DKRs and asymmetric transformations by enzyme-metal comninations since the first report from the Williams group in 1996.
Mahn-Joo Kim received his B.S. from Kangwon National University in 1977, his M.S. from Seoul National University in 1981, and his Ph.D. from Harvard University in 1987. After he had spent 1 year for postdoctoral training at Texas A \& M University, he joined Pohang University of Science and Technology (POSTECH) as an assistant professor of organic chemistry in 1988. Currently he is a full professor of organic chemistry at the same university. He is one of the NRL directors (2000-2005) and a recipient of Chang Se Hee Award (2004).

Yangsoo Ahn received his B.S. (1980), M.S. (1982) and Ph.D. (1987) from Seoul National University. He joined the R\&D Center of CJ as a senior research scientist in 1987. After having spent several years as a group leader at CJ, he joined POSTECH as a research professor of Professor Kim's NRL in 2000. He currently is a lecturer in chemistry at the same university.

Jaiwook Park received his B.S. and M.S. degrees from Seoul National University under the supervision of Prof. Eun Lee and his Ph.D. degree from Princeton University under the supervision of Prof. M. F. Semmelhack. After his postdoctoral training with Prof. Satoru Masamune at Massachusetts Institute of Technology, he joined POSTECH as an assistant professor of organic chemistry in 1989. Currently he is a full professor at the same university. He has been collaborating with Prof. Kim as a principal researcher of Professor Kim's NRL since 2000. 


\section{DKR by Enzyme-Metal Combo Catalysis}

\section{DKR by Lipase-Ruthenium Combination}

DKR of Secondary Alcohols. The first DKR of secondary alcohols, described by the Williams group in $1996,{ }^{6}$ was performed with rhodium complexes as the racemizing catalysts. In the DKR of 1-phenylethanol using vinyl acetate as an acyl donor, the optical purity of the acetylated product was only $80 \%$ ee even at $76 \%$ conversion.

One year later, Bäckvall et al. reported a significantly improved procedure using a diruthenium complex (1) and an immobilized and thermally stable lipase (Candida antarctica lipase B (CALB); trade name, Novozym-435) at $70{ }^{\circ} \mathrm{C} .{ }^{10} p$ Chlorophenyl acetate (PCPA) was a noticeable acyl donor that is compatible with the racemization catalyst. DKR of 1phenylethanol by the procedure gave optically pure $(R)-\alpha$ phenylethyl acetate (>99.5\% ee) in a high yield $(100 \%$ conversion, 92\% isolated yield) (Table 1). However, the DKR required a stoichiometric amount of acetophenone acting as hydrogen acceptors for racemization, otherwise a large amount (> 20\%) of acetophenone formed with decreasing the yield of $(R)$ - $\alpha$-phenylethyl acetate. ${ }^{10 \mathrm{~b}}$

Meanwhile, we found that an indenylruthenium complex (2) racemized secondary alcohols without the aid of ketones during DKR. ${ }^{11}$ The DKR with $\mathbf{2}$, however, required a catalytic amount of triethylamine and molecular oxygen to activate 2. The combination of an immobilized Pseudo-
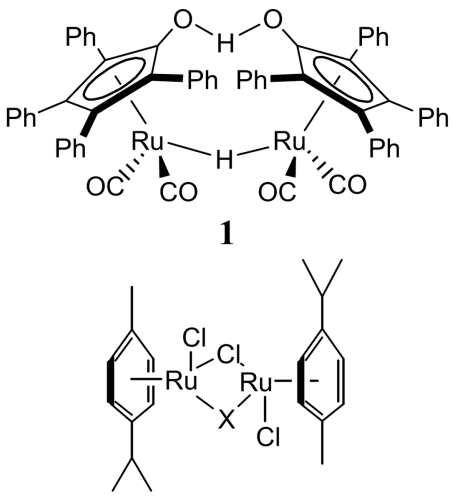

$$
\text { 3: } \mathrm{X}=\mathrm{Cl}
$$$$
\text { 4: } \mathrm{X}=\mathrm{H}
$$

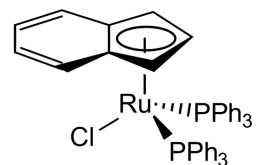

2

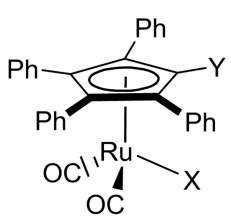

5: $\mathrm{X}=\mathrm{Cl}, \mathrm{Y}=\mathrm{NH}-i \mathrm{Pr}$

6: $\mathrm{Y}=\mathrm{H}, \mathrm{Y}=\mathrm{NH}-\mathrm{iPr}$

7: $\mathrm{X}=\mathrm{Cl}, \mathrm{Y}=\mathrm{Ph}$
Figure 1. Ruthenium complexes employed as the racemization catalysts for the DKR of secondary alcohols.

Table 1. DKR of 1-phenylethanol with diruthenium complex 1

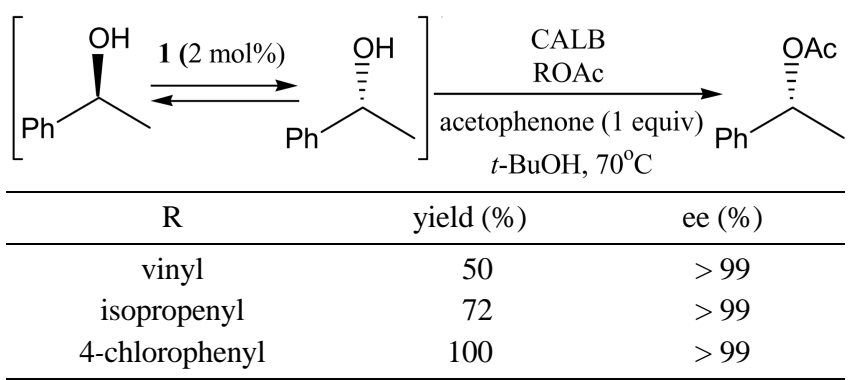

Table 2. DKR of secondary alcohols with indenyl ruthenium complex 2

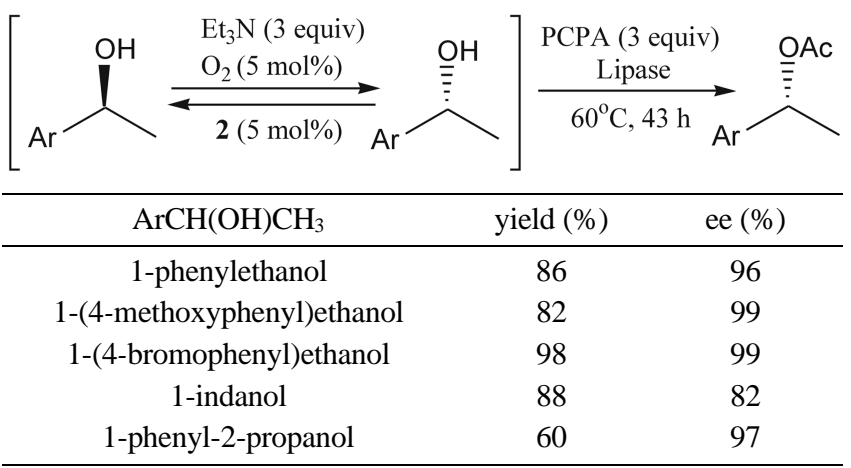

monas cepacia lipase (PCL, trade name, Lipase PS-C®) and 2 at $60{ }^{\circ} \mathrm{C}$ was effective for the DKR of benzylic alcohols, but was somewhat less effective for that of aliphatic alcohols (Table 2).

Then, we found a cymene-ruthenium complex (3) and its activated hydride form (4) effective as the racemizing catalysts. The activated complex $\mathbf{4}$, in particular, displayed satisfactory performances in the DKRs of aliphatic alcohols as well as benzylic alcohols (Table 3). A noticeable feature of the catalyst is the high racemizing activity toward allylic alcohols $^{12}$ so that their DKRs can be done at room temperature to provide high yields with excellent optical purities (Table 4). Another feature is its good activity in

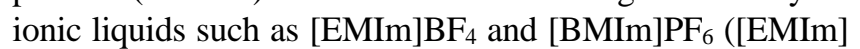

Table 3. DKR of alcohols with cymene-ruthenium catalyst 4

\begin{tabular}{|c|c|c|}
\hline & 4 (4 mol\%), PCL & $\stackrel{\mathrm{O} A c}{\equiv}$ \\
\hline & $\begin{array}{c}\text { PCPA ( } 1.5 \text { equiv) } \\
\mathrm{Et}_{3} \mathrm{~N}(1 \text { equiv) } \\
\mathrm{CH}_{2} \mathrm{Cl}_{2}, 40^{\circ} \mathrm{C}\end{array}$ & \\
\hline $\mathrm{R}$ & yield $(\%)$ & ee $(\%)$ \\
\hline phenyl & 95 & 94 \\
\hline p-chlorophenyl & 93 & 99 \\
\hline$p$-methoxyphenyl & 93 & 99 \\
\hline benzyl & 85 & $>99$ \\
\hline
\end{tabular}

Table 4. DKR of allylic alcohols with cymene-ruthenium catalyst 4

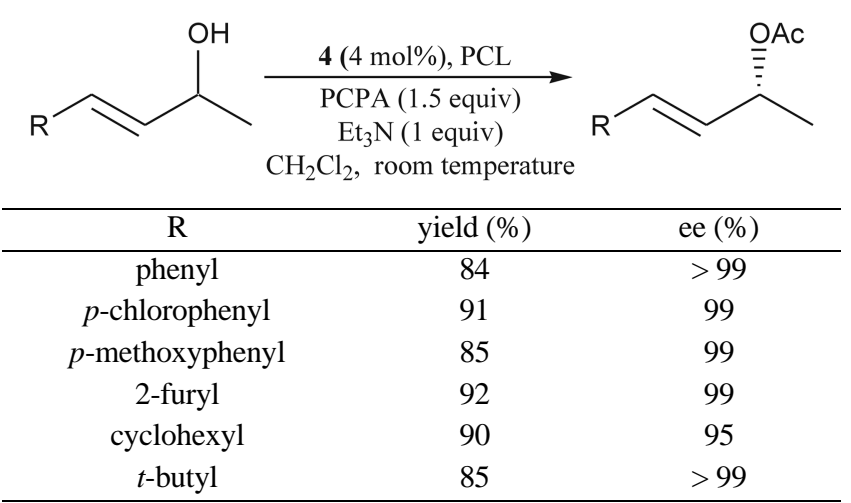


Table 5. DKR of alcohols with cymene-ruthenium catalyst $\mathbf{4}$ in $\left[\mathrm{BMIm}_{\mathrm{P}} \mathrm{PF}_{6}\right.$

\begin{tabular}{|c|c|c|}
\hline \multicolumn{2}{|c|}{$\begin{array}{r}4(8 \mathrm{~mol} \%), \text { LPS-TN-M } \\
\mathrm{CH}_{3} \mathrm{CO}_{2} \mathrm{CH}_{2} \mathrm{CF}_{3}, \mathrm{Et}_{3} \mathrm{~N}\end{array}$} & \multirow{2}{*}{ ee $(\%)$} \\
\hline $\mathrm{RCH}(\mathrm{OH}) \mathrm{CH}_{3}$ & yield $(\%)$ & \\
\hline 1-phenyl-2-propanol & 85 & 99 \\
\hline 1-phenyl-3-butanol & 85 & 99 \\
\hline 1-(3-methylphenyl)ethanol & 87 & 98 \\
\hline 1-(4-methylphenyl)ethanol & 87 & 99 \\
\hline 1-(4-methoxyphenyl)ethanol & 85 & 99 \\
\hline 1-(4-chlorophenyl)ethanol & 87 & 99 \\
\hline 1-(4-bromophenyl)ethanol & 92 & 99 \\
\hline 1-indanol & 85 & 99 \\
\hline 1-[4-(1-hydroxyethyl)phenyl]ethanol & 87 & $99(\mathrm{de} 99 \%)$ \\
\hline 1-[3-(1-hydroxyethyl)phenyl]ethanol & 86 & $99($ de $97 \%)$ \\
\hline
\end{tabular}

= 1-ethyl-3-methylimidazolium, [BMIm] = 1-butyl-3-methylimidazolium). ${ }^{13}$ The DKRs in the ionic liquids were also possible at room temperature, and the racemizing catalyst and enzyme in the ionic liquid layer were reusable after extracting the products with ether (Table 5). ${ }^{14}$

In efforts to develop racemizing catalysts active at room temperature under DKR conditions, we synthesized a novel aminocyclopentadienyl ruthenium chloride complex (5), and found that it transforms to the corresponding hydride

Table 6. DKR of alcohols with aminocyclopentadienyl ruthenium complex

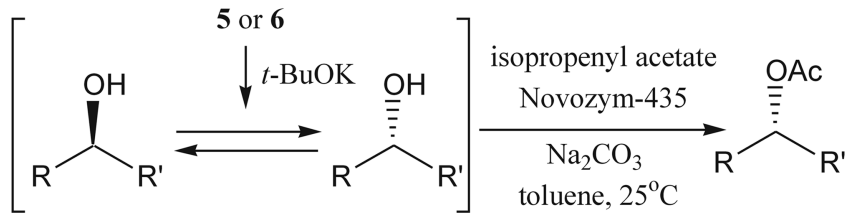

\begin{tabular}{ccccc}
\hline R & R' & catalyst & yield (\%) & ee $(\%)$ \\
\hline phenyl & methyl & $\mathbf{5}$ & 95 & $>99$ \\
phenyl & methyl & $\mathbf{6}$ & 92 & $>99$ \\
4-chlorophenyl & methyl & $\mathbf{5}$ & 94 & $>99$ \\
4-chlorophenyl & methyl & $\mathbf{6}$ & 91 & $>99$ \\
4-methoxyphenyl & methyl & $\mathbf{5}$ & 90 & $>99$ \\
4-methoxyphenyl & methyl & $\mathbf{6}$ & 94 & $>99$ \\
1-indanyl & & $\mathbf{5}$ & 89 & 95 \\
cyclohexyl & methyl & $\mathbf{5}$ & 86 & $>99$ \\
cyclohexyl & methyl & $\mathbf{6}$ & $98^{a}$ & $>99$ \\
4-nitrophenyl & methyl & $\mathbf{6}$ & 97 & $>99$ \\
4-cyanophenyl & methyl & $\mathbf{6}$ & 95 & $>99$ \\
phenyl & ethyl & $\mathbf{6}$ & 90 & $>99$ \\
n-hexyl & methyl & $\mathbf{5}$ & 89 & 91 \\
2-phenylethenyl & methyl & $\mathbf{5}$ & 93 & 98 \\
phenyl & vinyl & $\mathbf{5}$ & 62 & 81 \\
cyclohexyl & vinyl & $\mathbf{5}$ & 90 & $>99$ \\
trityloxymethyl & methyl & $\mathbf{5}$ & 97 & 99 \\
\hline
\end{tabular}

${ }^{a}$ Yield based on NMR data complex (6) by treatment with potassium $t$-butoxide in the presence of alcohols. ${ }^{9}$ The hydride species $\mathbf{6}$ was active without the aid of base in the DKRs of aliphatic alcohols as well as in those of aromatic alcohols at room temperature (Table 6). Interestingly, isopropenyl acetate was usable as an efficient acyl donor in the DKRs. Isopropenyl acetate is a much better acylating reagent than $p$-chlorophenyl acetate (PCPA) used in the previous DKRs: It is readily available, easily separable from the DKR products, and more active than PCPA. ${ }^{15}$ Although the mechanism for the catalytic racemization is not clear yet, according to our mechanistic studies, the amino group in $\mathbf{5}$ or $\mathbf{6}$ seems to be crucial for the racemization, while the recent report by the Bäckvall group suggests a different pathway. ${ }^{16}$ The Bäckvall group used a modified complex $\mathbf{7}$ as the efficient racemizing catalyst, which is similar to $\mathbf{5}$ but has no amino group.

A new catalyst system of $\left[\mathrm{Tos} N\left(\mathrm{CH}_{2}\right)_{2} \mathrm{NH}_{2}\right] \mathrm{RuCl}(p$ cymene) and 2,2,6,6-tetramethyl-1-piperidinyloxy (TEMPO) was reported by Sheldon et al. for the DKR of alcohols. ${ }^{17}$ However, it was tested only for 1-phenylethanol to get 1phenylethyl acetate in $76 \%$ yield.

DKR of Functionalized Alcohols. The DKRs of functionalized alcohols such as diols, hydroxy esters, hydroxy

Table 7. DKR of diols with diruthenium complex 1

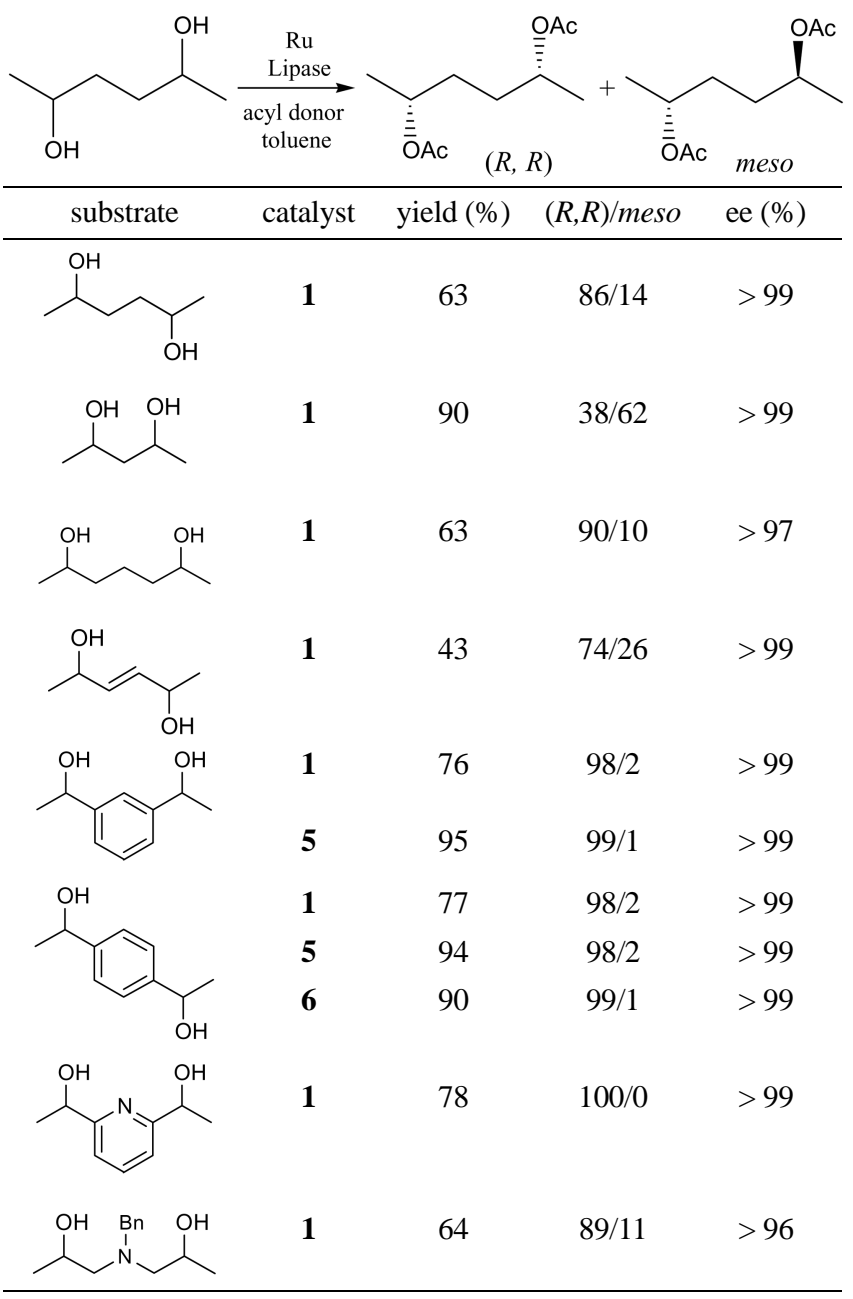


Table 8. DKR of $\alpha$-hydroxy esters

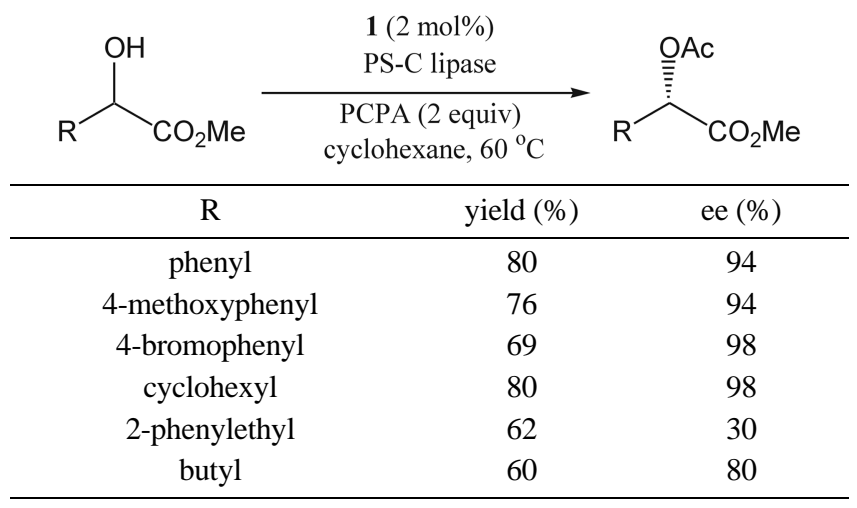

aldehydes, azido alcohols, and hydroxy nitriles were well performed by lipase-ruthenium bicatalysis. The DKR of diols was achieved with diruthenium catalyst $\mathbf{1}$ and CALB in the presence of PCPA to give the corresponding diacetates of $(R, R)$-configuration from the mixture of $d l$ - and mesoisomers (Table 7). ${ }^{18}$ The DKRs of rigid benzylic diols with 1 gave better results in terms of de compared to those of more flexible aliphatic diols, reflecting that lipase displays higher stereoselectivity toward benzylic diols than aliphatic diols.

The DKRs of $\alpha-\beta-\gamma$, and $\delta$-hydroxy esters were also accomplished with PCL and 1 at $60-70{ }^{\circ} \mathrm{C} .{ }^{19}$ In the DKRs, the enantioselectivities were good in most cases, but the yields were moderate. The use of $\mathrm{H}_{2}$ was necessary in the DKRs of $\gamma$ and $\delta$-hydroxy esters to suppress the formation of ketones (Table 8, 9, and Figure 2).

The DKRs of small functionalized alcohols such as 2hydroxybutanoic acid, 2-hydroxypropanal, and 1,2-propanediol were carried out after the protection of the terminal groups with a bulky group (Table 10 and Figure 3 ) since the bulky protecting groups enhanced the enantioselectivity of enzyme in the DKR. ${ }^{20}$ In the DKR of hydroxy acids, $t$-butyl group was the best as the protecting group of the carboxylic acid functionality. The trityl group was a proper choice for the protection of primary alcohols in diols such as 1,2propanediol, 1,2-butanediol, and 1,3-butanediol. ${ }^{20} 1,2$-Benzenedimethanol was used for protecting the formyl groups of $\alpha$ - and $\beta$-hydroxy aldehydes. ${ }^{20}$ High enantiomeric excesses (95\% and higher) were obtained in the DKRs of the protected diols and hydroxy aldehydes. 2,6-Dimethyl-4heptanol was used as a hydrogen source to suppress the

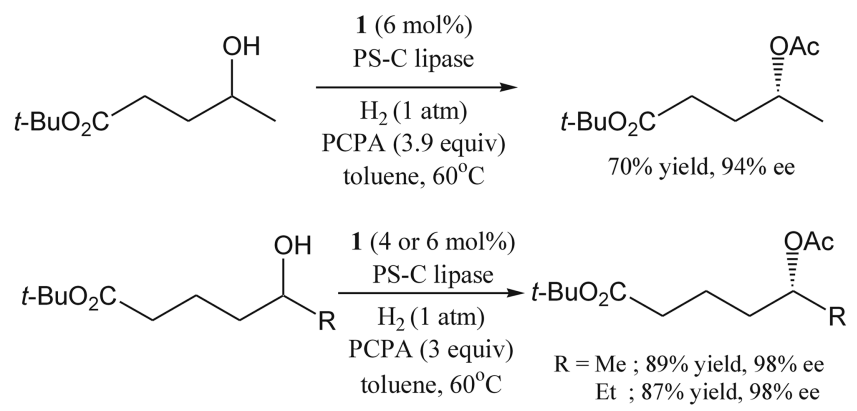

Figure 2. DKR of $\gamma$ and $\delta$-hydroxy esters.
Table 9. DKR of $\beta$-hydroxy esters

\begin{tabular}{ccc}
\multicolumn{3}{c}{$\begin{array}{c}\text { PCPA (3 equiv) } \\
\text { P-buthyl methy ether } \\
60^{\circ} \mathrm{C}, 6 \text { days }\end{array}$} \\
\cline { 2 - 3 } $\mathrm{R}_{\text {phenyl }}$
\end{tabular}

Table 10. DKR of hydroxy acids, diols, and hydroxy aldehydes

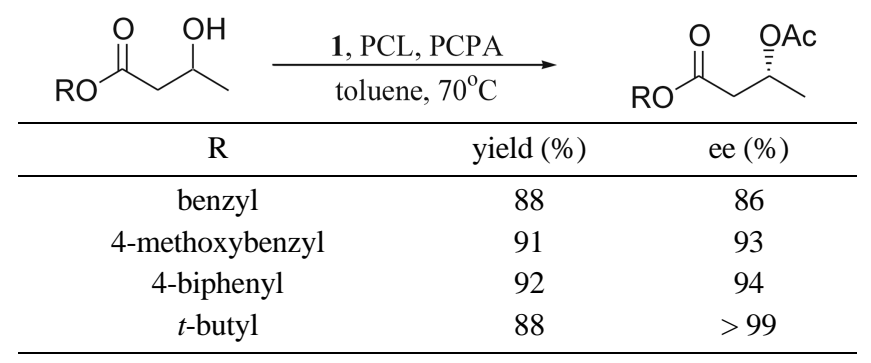

formation of the oxidized side products.

The DKRs of $\beta$-azidoalcohols ${ }^{19 d}$ and $\beta$-hydroxynitriles ${ }^{21 \mathrm{a}}$ were also accomplished by employing 1 and CALB with PCPA as the acyl donor. The DKRs of $\beta$-azidoalcohols were performed at $60^{\circ} \mathrm{C}$ while those of $\beta$-hydroxynitriles required a higher temperature $\left(100^{\circ} \mathrm{C}\right)$ to increase the racemization rate. The optical purities of products were satisfactory in all cases. In the cases of $\beta$-hydroxynitriles, dehydrogenation lowered the yield.

\section{DKR by Subtilisin-Ruthenium Combination}

DKR of Secondary Alcohols. The lipase-catalyzed DKRs provide only $(R)$-products. To obtain $(S)$-products, we need an enzyme with a complementary $(S)$-stereoselectivity. We surveyed $(S)$-selective enzymes usable in DKR at room temeparature with the racemizing catalyst $\mathbf{5}$. Subtilisin was a candidate, but its commercial form was not applicable to DKR due to its low enzymatic activity and instability in nonaqueous medium. However, we succeeded in enhancing its activity and stability by treating it with a surfactant before use. At room temperature DKR with subtilisin, trifluoroethyl butanoate was employed as an acylating agent and the $(S)$-products were obtained in good yields with high optical purities (Table 11). ${ }^{22}$

The $(S)$-selective DKR of alcohols with subtilisin was also possible in ionic liquid at room temperature (Table 12). ${ }^{14}$ In this case, the cymene-ruthenium complex 3 was used as the racemization catalyst. In general, the optical purities of $(S)$ esters were lower than those of $(R)$-esters described in Table 5.

DKR by Lipase-Palladium Combination

DKR of Allylic Acetates. The DKR of allylic acetates 

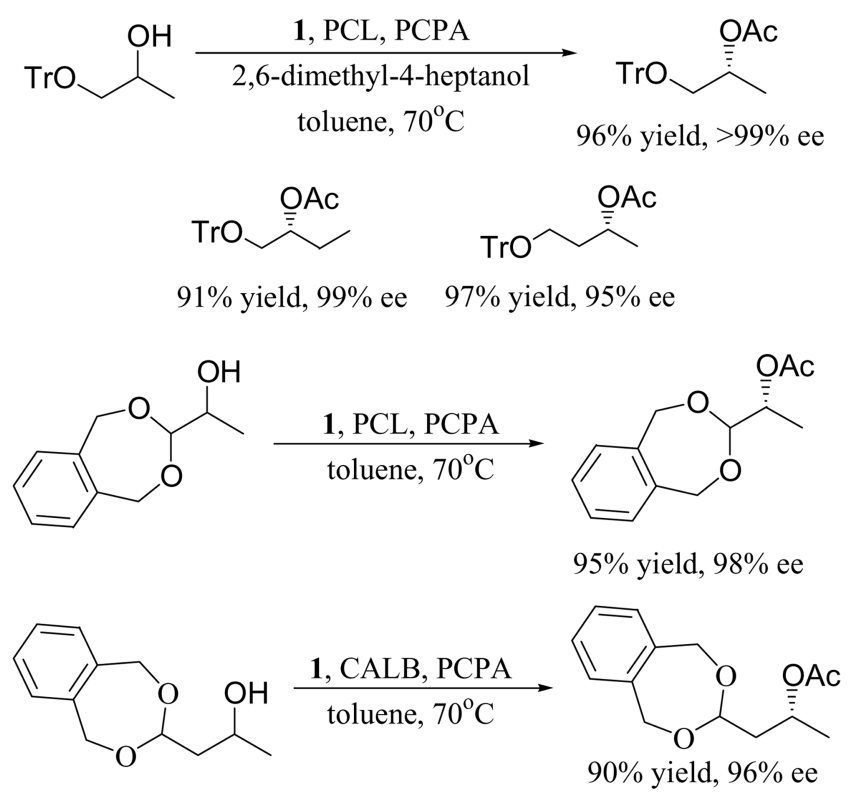

Figure 3. DKR of protected diols and hydroxy aldehydes by lipaseruthenium combination.

Table 11. DKR of secondary alcohols by subtilisin-ruthenium bicatalysis

\begin{tabular}{|c|c|c|}
\hline $\begin{array}{c}5 \text { (4 mol\%) } \\
\text { subtilisin }\end{array}$ & $\begin{array}{l}\text { ) } \\
\mathrm{CF}_{3} \\
\mathrm{C}\end{array}$ & \\
\hline $\mathrm{R}$ & yield $(\%)$ & ee $(\%)$ \\
\hline phenyl & 95 & 92 \\
\hline 4-chlorophenyl & 92 & 99 \\
\hline 4-methoxyphenyl & 93 & 94 \\
\hline benzyl & 89 & 92 \\
\hline 2-phenylethyl & 80 & 98 \\
\hline cyclohexyl & 80 & 98 \\
\hline n-hexyl & 77 & 98 \\
\hline 2-phenylethynyl & 90 & 95 \\
\hline
\end{tabular}

was accomplished through coupling Pd-catalyzed racemization and enzymatic hydrolysis of allylic acetates in buffer solution. ${ }^{6}$ However, the DKR under these conditions was limited to cyclohexenyl acetates to give symmetrical palladium-allyl intermediates. Among them, 2-phenyl-2-cyclohexenyl acetate was the only substrate to have been resolved with good results (96\% conversion, $81 \%$ yield, $96 \%$ ee) (Figure 4).

We improved the DKR of allylic acetates significantly by replacing the enzymatic hydrolytic reaction with the enzymatic transesterification reaction and employing $\mathrm{Pd}\left(\mathrm{PPh}_{3}\right)_{4}$, and 1,1'-bis(diphenylphosphino)ferrocene (dppf) as the racemizing catalyst system in tetrahydrofuran (THF). ${ }^{23} 2-$ Propanol was used as an acyl acceptor. The use of the chelating ligand (dppf) decreased the formation of byproducts (1,3-dienes) during the DKR. Various acyclic allylic acetates were transformed to their corresponding
Table 12. DKR by subtilisin-ruthenium bicatalysis in $\left[{\mathrm{BMIm}] \mathrm{PF}_{6}}_{6}\right.$

4, subtilisin-CLEC
[BMIM] $\mathrm{PF}_{6}$, r.t.

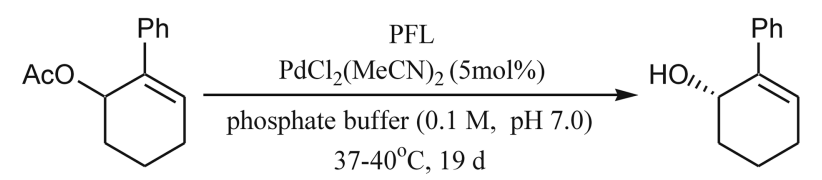

Figure 4. DKR of 2-phenyl-2-cyclohexenyl acetate by lipasepalladium bicatalysis.

Table 13. DKR of allylic acetates by lipase-palladium bicatalysis

\begin{tabular}{ccc} 
& $\begin{array}{c}\text { Lipase, } i \text {-PrOH } \\
\begin{array}{c}\mathrm{Pd}\left(\mathrm{PPh}_{3}\right)_{4}, \mathrm{dppf} \\
\mathrm{THF}, \text { r.t. }\end{array}\end{array}$ \\
\hline $\mathrm{R}$ & yield $(\%)$ & ee (\%) \\
\hline phenyl & 83 & 98 \\
4-chlorophenyl & 77 & 98 \\
4-methylphenyl & 82 & $>99$ \\
2-furyl & 87 & 98 \\
1-naphthyl & 70 &
\end{tabular}

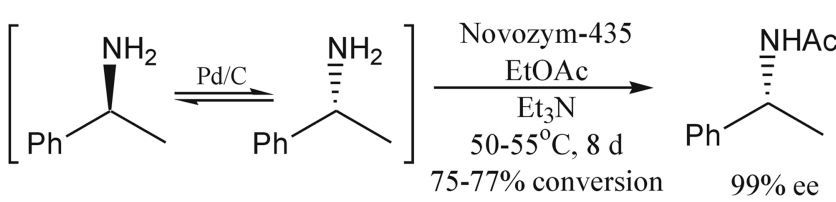

Figure 5. DKR of 1-phenylethylamine by lipase-palladium bicatalysis.

allylic alcohols at room temperature in good yields and excellent enantioselectivities (Table 13).

DKR of Amines. Reetz et al. reported for the first time the DKR of 1-phenylethylamine by employing palladium on carbon and CALB ${ }^{8}$ However, the DKR required a very long reaction time ( 8 days) at $50-55{ }^{\circ} \mathrm{C}$ and provided a poor isolated yield (60\%) (Figure 5). Recently, Bäckvall et al. reported that diruthenium complex 1 racemizes aromatic amines at $110{ }^{\circ} \mathrm{C}$ in toluene, but the racemization conditions 
Table 14. Asymmetric reductive acetylation of ketones

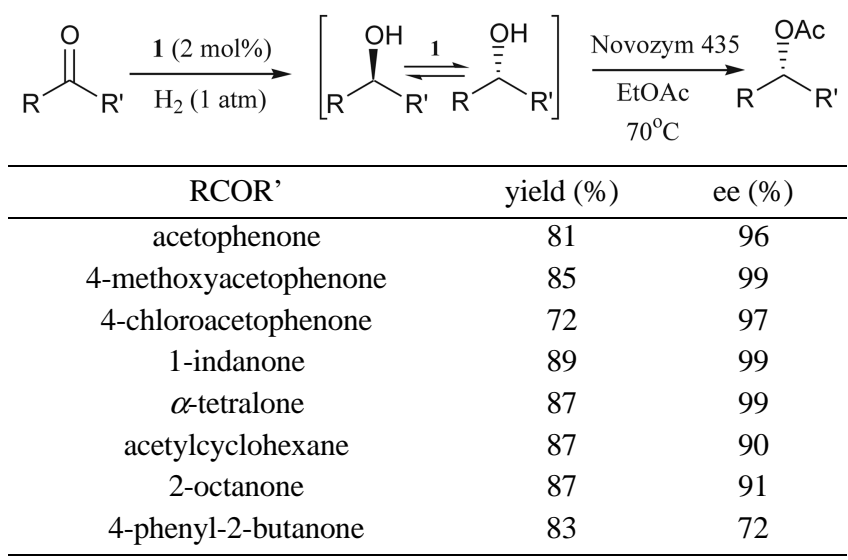

were not applicable to the DKR involving enzymes. ${ }^{24}$

\section{Asymmetric Transformations by Enzyme-Metal Combo Catalysis}

\section{Asymmetric Transformation by Lipase-Ruthenium} Combination

Asymmetric Reductive Acetylation of Ketones. The catalytic alcohol racemization with diruthenium catalyst $\mathbf{1}$ is based on the reversible transfer hydrogenation mechanism. Meanwhile the problem of ketone formation in the DKR of secondary alcohols with $\mathbf{1}$ is caused by molecular hydrogen liberation. Then we envisioned a novel asymmetric reductive acetylation of ketones to circumvent the problem of ketone formation. A key factor of this process was the selection of hydrogen donors compatible with the DKR conditions. 2,6-Dimethylheptan-4-ol, which can not be acylated by lipases, acted as a proper hydrogen donor in the DKR of alcohols with PCPA. ${ }^{25}$ Asymmetric reductive acetylation of ketones was also possible under 1 atm hydrogen in ethyl acetate, although a long reaction time (96 h) was required. Ethanol formation did not cause critical problem, and various ketones were transformed successfully into the corresponding chiral acetates (Table 14). ${ }^{25 \mathrm{~b}}$

Asymmetric reductive acetylation process was also appli-
Table 15. Asymmetric transformations of acyloxyphenyl ketones

(\%)

cable to acetoxyaryl ketones. ${ }^{26}$ For example, 3'-acetoxyacetophenone was transformed to $(R)$-1-(3-hydroxyphenyl)ethyl acetate under 1 atm $\mathrm{H}_{2}$ in $95 \%$ yield. The overall reaction seems to be a simple asymmetric reductive internal acyl migration. In fact, however, it is the result from nine catalytic steps: two ruthenium-catalyzed reductions, two ruthenium-catalyzed epimerizations, three lipase-catalyzed deacylations, and two lipase-catalyzed acylations (Figure 6). This process was applicable to a wide range of acyloxy-

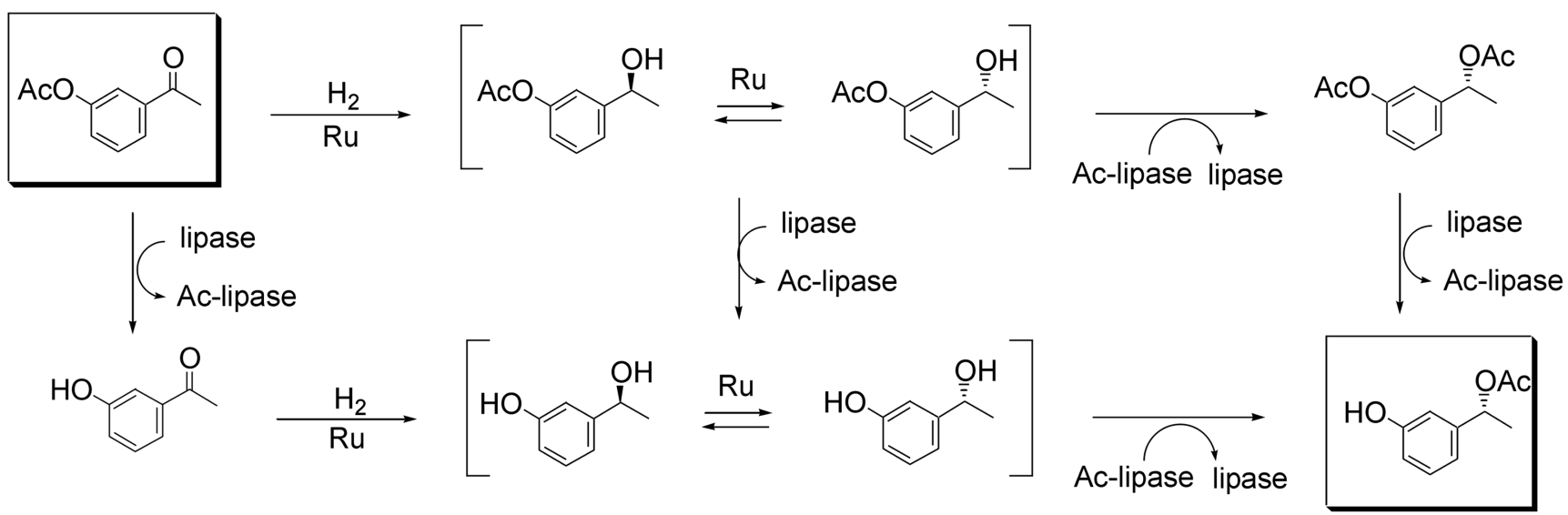

Figure 6. Reaction Pathway for the Asymmetric Transformation of 3'-Acetoxyacetophenone. 


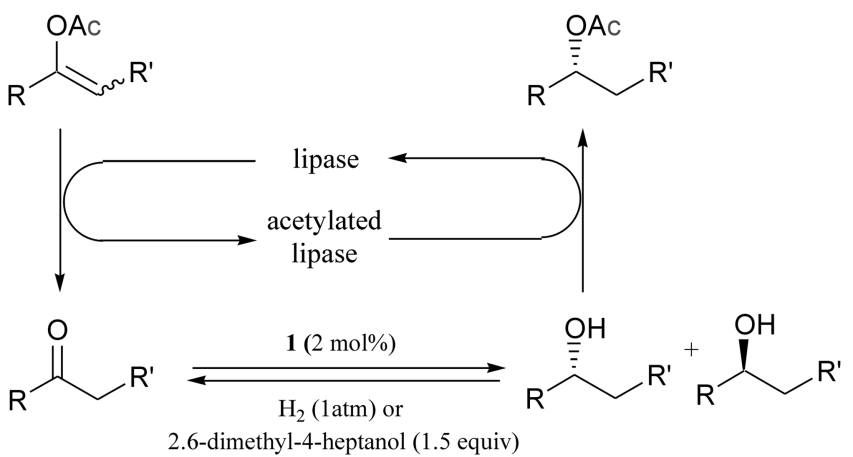

Figure 7. Asymmetric hydrogenation of enol acetates.

Table 16. Asymmetric hydrogenation of enol acetates

\begin{tabular}{cccc}
\hline $\mathrm{R}$ & $\mathrm{R}^{\prime}$ & yield (\%) & ee (\%) \\
\hline phenyl & $\mathrm{H}$ & 89 & 98 \\
4-methoxyphenyl & $\mathrm{H}$ & 80 & 98 \\
4-chlorophenyl & $\mathrm{H}$ & 91 & 97 \\
1-indenyl & & 87 & 99 \\
benzyl & $\mathrm{H}$ & 90 & 79 \\
2-phenylethyl & $\mathrm{H}$ & 92 & 94 \\
cyclohexyl & $\mathrm{H}$ & 94 & 99 \\
n-hexyl & $\mathrm{H}$ & 95 & 91 \\
\hline
\end{tabular}

phenyl ketones (Table 15).

Asymmetric Hydrogenation of Enol Acetates. After succeeding in the asymmetric reductive acylation of ketones, we studied to see if enol acetates can be used as acyl donors and precursors of ketones at the same time through deacylation and keto-enol tautomerization (Figure 7). The overall reaction thus corresponds to the asymmetric reduction of enol acetate. For example, 1-phenylvinyl acetate was transformed to $(R)$-1-phenylethyl acetate by CALB and diruthenium complex 1 in the presence of 2,6-dimethyl-4heptanol in $89 \%$ yield (98\% ee). ${ }^{25 a}$ Molecular hydrogen (1 atm) was almost equally effective for the transformation (86\% yield, 96\% ee). ${ }^{25 \mathrm{~b}} \mathrm{~A}$ broad range of enol acetates were prepared from ketones and were successfully transformed to

Table 17. Asymmetric reductive acetylation of ketoximes

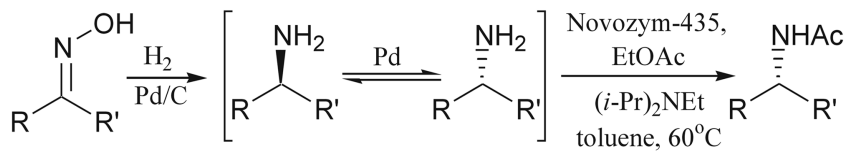

\begin{tabular}{cccc}
\hline $\mathrm{R}$ & $\mathrm{R}{ }^{\prime}$ & yield (\%) & ee $(\%)$ \\
\hline phenyl & methyl & 80 & 98 \\
4-methylphenyl & methyl & 84 & 97 \\
3-methylphenyl & methyl & 81 & 94 \\
4-methoxylpheny & methyl & 82 & 96 \\
phenyl & ethyl & 76 & 98 \\
& & 84 & 95 \\
1-indanyl & & 70 & 97 \\
$\alpha$-tetralyl & & 89 & 99 \\
4-chromayl & & &
\end{tabular}

the corresponding $(R)$-acetates under 1 atm $\mathrm{H}_{2}$ (Table 16). From unsymmetrical aliphatic ketones, enol acetates were obtained as the mixtures of regio- and geometrical isomers. Notably, however, the efficiency of the process was little affected by the isomeric composition of the enol acetates.

\section{Asymmetric Transformation by Lipase-Palladium Combination}

Asymmetric Reductive Acetylation of Ketoximes. The strategy for the asymmetric reductive acylation of ketones was extended to ketoximes by coupling the reduction of ketoximes to the DKR of amines. The asymmetric reactions of ketoximes were performed with CALB and $\mathrm{Pd} / \mathrm{C}$ in the presence of hydrogen, diisopropylethylamine, and ethyl acetate in toluene at $60{ }^{\circ} \mathrm{C}$ for 5 days (Table 17). ${ }^{27} \mathrm{In}$ comparison to the direct DKR of amines, the yields of chiral amides increased significantly. Diisopropylethylamine was a factor for the increase. However, the major factor would be the slow generation of amines, which maintains the amine concentration low enough to suppress side reactions including the reductive deamination. Disappointingly, this process is limited to benzylic amines. Low turnover frequencies also need to be overcome.

\section{Conclusion}

This account describes that enzyme-metal combo-catalysis provides a novel approach for the conversion of racemic substrates to single enantiomeric products. It has been demonstrated that the racemic alcohols, esters, and amines can be efficiently converted to the corresponding enantiomeric products through the enzyme-metal catalyzed DKR. The key feature of this methodology is the combination of metal-catalyzed racemization and enzymatic resolution in a single reaction flask. For the DKR of alcohols, a pair of complementary procedures are now available for the synthesis of both $(R)$ - and $(S)$-esters. The DKR can be done at room temperature with commercially available enzymes and racemizing catalyst in good yields and high optical purities in most cases. However, the DKR of amines is limited to benzylic amines and require high temperature. Accordingly, for the efficient DKR of amines, further efforts will be directed toward developing practical racemizing catalysts with high reactivity and broad specificity at room temperature. ${ }^{28}$

Acknowledgement. We acknowledge the financial supports from the Ministry of Science and Technology through KISTEP (the NRL program) and KOSEF (the SRC program, CIMS), and the Ministry of Education and Human Resources through KRF (the BK21 program).

\section{References}

1. Sheldon, R. A. Chirotechnology, Industrial Synthesis of Optically Active Compounds; Dekker: New York, 1993.

2. (a) Wong, C.-H.; Whitesides, G. M. Enzymes in Synthetic Organic Chemistry; Pergamon: Oxford, UK, 1994. (b) Koskinen, A. M. P.; 
Klibanov, A. M. Enzymatic Reactions in Organic Media; Blackie Academic \& Professional: Glasgow, Scotland, 1996. (c) Faber, K. Biotransformations in Organic Chemistry, 3rd ed.; Springer: Berlin, Germany, 1997. (d) Bornscheuer, U. T.; Kazlauskas, R. J. Hydrolases in Organic Synthesis; Wiley-VCH: Weiheim, Germany, 1999. (e) Drauz, K.; Waldmann, H. Enzyme Catalysis in Organic Synthesis: A Comprehensive Handbook, 2nd ed.; Wiley-VCH: Weinheim, Germany, 2002; Vols. I-III.

3. (a) Kim, M.-J.; Choi, G.-B.; Kim, J.-J.; Kim, H. J. Tetrahedron Lett. 1995, 36, 6253. (b) Kim, M.-J.; Lim, I.-T. Synlet 1996, 138. (c) Kim, M.-J.; Lim, I.-T.; Choi, G.-B.; Whang, S.-Y.; Ku, B.-C.; Choi, J.-Y. Bioorg. Med. Chem. Lett. 1996, 6, 71. (d) Kim, M.-J.; Lim, I. T.; Kim, H.-J.; Wong, C.-H. Tetrahedron: Asymmetry 1997, 8, 1507. (e) Lee, D.; Kim, M.-J. Tetrahedron Lett. 1998, 39 , 2163. (f) Chung, S.-K.; Chang, Y.-T.; Lee, E. J.; Shin, B.-G.; Kwon, Y.-U.; Kim, K.-C.; Lee, D. H.; Kim, M.-J. Bioorg. Med. Chem. Lett. 1998, 8, 1503. (g) Lee, D.; Kim, M.-J. Tetrahedron Lett. 1998, 39, 9039. (h) Lee, D.; Kim, M.-J. Org. Lett. 1999, 1, 925. (i) Im, A. S.; Cheong, C. S.; Lee, S. H. Bull. Korean Chem. Soc. 2003, 24, 1269. (j) Kang, H.-Y.; Ji, Y.; Yu, Y.-K.; Yu, J.-Y.; Lee, Y.; Lee, S.-J. Bull. Korean Chem. Soc. 2003, 24, 1819.

4. Ward, R. S. Tetrahedron: Asymmetry 1995, 6, 1475.

5. (a) Stürmer, R. Angew. Chem. Int. Ed. Engl. 1997, 36, 1173. (b) El Gihani, M. T.; Williams, J. M. J. Curr. Opin. Biotechnol. 1999, 3, 11. (c) Azerad, R.; Buisson, D. Curr. Opin. Biotechnol. 2000, 11, 565. (d) Huerta, F. F.; Minidis, A. B. E.; Bäckvall, J.-E. Chem. Soc. Rev. 2001, 30, 321. (e) Kim, M.-J.; Ahn, Y.; Park, J. Curr. Opin. Biotechnol. 2002, 13, 578. (f) Pellissier, H. Tetrahedron 2003, 59, 8291. (g) Pàmies, O.; Bäckvall, J.-E. Chem. Rev. 2003, 103, 3247. (h) Pàmies, O.; Bäckvall, J.-E. Curr. Opin. Biotechnol. 2003, 14, 407. (i) Turner, N. J. Curr. Opin. Chem. Biol. 2004, 8, 114.

6. Allen, J. V.; Williams, J. M. J. Tetrahedron Lett. 1996, 37, 1859.

7. Dinh, P. M.; Howarth, J. A.; Hudnott, A. R.; Williams, J. M. J.; Harris, W. Tetrahedron Lett. 1996, 37, 7623.

8. Reetz, M. T.; Schimossek, K. Chimia 1996, 50, 668.

9. Choi, J. H.; Kim, Y. H.; Nam, S. H.; Shin, S. T.; Kim, M.-J.; Park, J. Angew. Chem. Int. Ed. Engl. 2002, 41, 2373.

10. (a) Larsson, A. L. E.; Persson, B. A.; Bäckvall, J.-E. Angew. Chem. Int. Ed. Engl. 1997, 36, 1211. (b) Persson, B. A.; Larsson, A. L. E.; Ray, M. L.; Bäckvall, J.-E. J. Am. Chem. Soc. 1999, 121, 1645. (c) Lee, H. K.; Ahn, Y. Bull. Korean Chem. Soc. 2004, 25, 1471.

11. Koh, J. H.; Jeong, H. M.; Kim, M.-J.; Park, J. Tetrahedron Lett. 1999, 40, 6281

12. Lee, D.; Huh, E. A.; Kim, M.-J.; Jung, H. M.; Koh, J. H.; Park, J. Org. Lett. 2000, 2, 2377.
13. (a) Kim, K. W.; Song, B.; Choi, M. Y.; Kim, M.-J. Org. Lett. 2001, 3, 1507. (b) Lee, J. K.; Kim, M.-J. J. Org. Chem. 2002, 67, 6845. (c) Kim, M.-J.; Choi, M. Y.; Lee, J. K.; Ahn, Y. J. Mol. Catal. B.: Enzym. 2003, 26, 115. (d) Erbeldinger, M.; Mesiano, A. J.; Russel, A. Biotechnol. Prog. 2000, 16, 1129. (e) Lau, R. M.; Rantwijk, F. van; Seddon, K. R.; Sheldon, R. A. Org. Lett. 2000, 2, 4189. (f) Itoh, T.; Akasaki, E.; Kudo, K.; Shirakami, S. Chem. Lett. 2001, 262. (g) Schoefer, S. H.; Kraftzik, N.; Wasserscheid, P.; Kragl, U. Chem. Commun. 2001, 425. (h) Park, S.; Kazlauskas, R. J. Org. Chem. 2001, 66, 8395.

14. Kim, M.-J.; Kim, H. M.; Kim, D.; Ahn, Y.; Park, J. Green Chem. 2004, 6, 471.

15. Choi, J. H.; Choi, Y. K.; Kim, Y. H.; Park, E. S.; Kim, E. J.; Kim, M.-J.; Park, J. J. Org. Chem. 2004, 69, 1972.

16. (a) Csjernyik, G.; Bogár, K.; Bäckvall, J.-E. Tetrahedron Lett. 2004, 45, 6799. (b) Martin-Matute, B.; Edin, M.; Bogár, K.; Bäckvall, J.-E. Angew. Chem. Int. Ed. 2004, 43, 6535.

17. Dijksman, A.; Elzinga, J. M.; Li, Y. X.; Arends, W. C. E.; Sheldon, R. A. Tetrahedron: Asymmetry 2002, 13, 879.

18. Persson, B. A.; Huerta, F. F.; Bäckvall, J.-E. J. Org. Chem. 1999, 64, 5237. (b) Edin, M.; Bäckvall, J.-E. J. Org. Chem. 2003, 68, 2216.

19. (a) Huerta, F. F.; Laxmi, S. Y. R.; Bäckvall, J.-E. Org. Lett. 2000, 2, 1037. (b) Runmo, A. B. L.; Pàmies, O.; Faber, K.; Bäckvall, J.E. Tetrahedron Lett. 2002, 43, 2983. (c) Pàmies, O.; Bäckvall, J.E. J. Org. Chem. 2002, 67, 1261. (d) Pàmies, O.; Bäckvall, J.-E. J. Org. Chem. 2001, 66, 4022.

20. Kim, M.-J.; Choi, Y. K.; Choi, M. Y.; Kim, M.; Park, J. J. Org. Chem. 2001, 66, 4736.

21. (a) Pàmies, O.; Bäckvall, J.-E. Adv. Synth. Catal. 2001, 343, 726. (b) Pàmies, O.; Bäckvall, J.-E. J. Org. Chem. 2002, 67, 9006. (c) Pàmies, O.; Bäckvall, J.-E. J. Org. Chem. 2003, 68, 4815.

22. Kim, M.-J.; Chung, Y. I.; Choi, Y. K.; Lee, H. K.; Kim, D.; Park, J. J. Am. Chem. Soc. 2003, 125, 11494.

23. Choi, Y. K.; Suh, J. H.; Lee, D.; Lim, I. T.; Jung, J. Y.; Kim, M.-J. J. Org. Chem. 1999, 64, 8423.

24. Pàmies, O.; Ell, A. H.; Samec, J. S. M.; Hermanns, N.; Bäckvall, J.-E. Tetrahedron Lett. 2002, 43, 4699.

25. (a) Jung, H. M.; Koh, J. H.; Kim, M.-J.; Park, J. Org. Lett. 2000, 2 , 409. (b) Jung, H. M.; Koh, J. H.; Kim, M.-J.; Park, J. Org. Lett. 2000, 2, 2487.

26. Kim, M.-J.; Choi, M. Y.; Han, M. Y.; Choi, Y. K.; Lee, J. K.; Park, J. J. Org. Chem. 2002, 67, 9481.

27. Choi, Y. K.; Kim, M.; Ahn, Y.; Kim, M.-J. Org. Lett. 2001, 3, 4099.

28. Kim, W.-H.; Karvembu, R.; Park, J. Bull. Korean Chem. Soc. 2004, $25,931$. 